TP Periodica Polytechnica Chemical Engineering

62(1), pp. 114-122, 2018

https://doi.org/10.3311/PPch.10400

Creative Commons Attribution (i)

RESEARCH ARTICLE

\section{Data-driven Modelling of Microfiltration Process with Embedded Static Mixer for Steepwater from Corn Starch Industry}

\author{
Laslo Šereš ${ }^{1}$, Ljubica Dokić ${ }^{2}$ Bojana Ikonić ${ }^{3}$, Dragana Šoronja- \\ Simović ${ }^{2}$, Miljana Djordjevićéc* Žana Šaranovićc ${ }^{4}$, Nikola Maravićc \\ Received 12 December 2016; accepted after revision 25 February 2017
}

\begin{abstract}
Cross-flow microfiltration using ceramic tubular membrane was applied for treatment of steepwater from corn starch industry. Experiments are conducted according to the faced centered central composite design at three different transmembrane pressures (1, 2 and 3 bar) and cross-flow velocities (100, 150 and $200 \mathrm{~L} / \mathrm{h}$ ) with and without the usage of Kenics static mixer. For examination of the influence of the selected operating conditions at which usage of the static mixer is justified, a response surface methodology and desirability function approach were used. Obtained results showed improvement in the average permeate flux by using Kenics static mixer for $211 \%$ to $269 \%$ depending on experimental conditions when compared to the system without the static mixer. As a result of optimization, the best results considering flux improvement as well as reduction of specific energy consumption were obtained at low transmembrane pressure and lower feed cross-flow rates.
\end{abstract}

\section{Keywords}

optimization, RSM, cross-flow microfiltration, steepwater, static mixer, corn starch industry

\footnotetext{
${ }^{1}$ Department of Business Informatics and Quantitative Methods,

Faculty of Economics in Subotica, University of Novi Sad,

Segedinski put 9-11, 24000 Subotica, Serbia

${ }^{2}$ Department of Carbohydrate Food Engineering,

Faculty of Technology, University of Novi Sad,

bul. cara Lazara 1, 21000 Novi Sad, Serbia

${ }^{3}$ Department of Chemical Engineering,

Faculty of Technology, University of Novi Sad,

bul. cara Lazara 1, 21000 Novi Sad, Serbia

${ }^{4}$ Economics Institute,

kralja Milana 16, 11000 Belgrade, Serbia

*Corresponding author, e-mail: miljanadj@tf.uns.ac.rs
}

\section{Introduction}

For years now, industries are familiar with the water recirculation concept which has been used in many factories. With increasing awareness of environmental issues that wastewaters can produce and desire to save fresh water resources, water recirculation became a growing demand, but before recirculation wastewaters must be treated first. The key goal of wastewater treatment is to archive reduction of the pollution to the required level for water recirculation within the factory or discharging into the recipient without any consequence [1]. In order to accomplish this aim, many techniques for wastewater treatment have been applied and usage of membrane separation processes is becoming the most common solution.

As proposed in the Best Available Techniques-BAT (issued by the Commission of the European Union) [2], membrane separation processes more often become applied in wastewater treatment from many industries especially because of the requirement for higher water quality. In cross-flow microfiltration fractionation of the feed stream is obtained by passing through the porous membrane which can be made from different materials. Usage of the ceramic membranes is a reasonable choice because they are sustainable in extremely aggressive conditions and have good thermal stability, mechanical strength, chemical resistance, long lifetime and defouling properties [3]. The main problems during these filtration processes are concentration polarisation and fouling of the membrane due to the forming of a layer on membrane surface. Layer represents secondary barrier to the flow and is caused by adsorption and deposition of the particles originating from wastewater on the membrane. [4]. Membrane fouling represents an inevitable problem, but it could be adjusted to a reasonable extent using different techniques [5], and one is fluid instability produced by turbulence promoters. For mass transfer improvement, an increase in cross-flow velocity in the vicinity of membrane surface provided by turbulence seems to be the simplest way [6]. There are two main groups of turbulence promoters, dynamic and static turbulence promoters. The advantage over dynamic promoters is given to static ones because of simple shape and installation, usage in a wide flow and viscosity ranges, resistance to depletion and lower operational 
and maintenance costs. Static mixer represents immobile inert elements which can be inserted into a tube or pipe and enable fluid mixing by producing transverse flows. Usage of the static mixers is widespread, including simple blending and multiphase mixing problems in both the laminar and turbulent flow regimes, because of their adaptability. Nowadays there are a large number of static mixer designs that are more or less complex. More than 30 models are commercially available followed by about 2000 US patents that have been granted. Best known among static mixers are Kenics, HEV, KMS and KMX mixers by Chemineer Inc., Dayton, $\mathrm{OH}$ and the SMX and SMX plus mixers by Sulzer Chemtech, Switzerland [7]. A static mixer, as one of the static turbulence promoters, consists of serially connected fixed elements, accommodated in a tube which provides fluid mixing when is placed inside the tubular membrane [8]. In this work, a Kenics static mixer is utilized to study permeate flux changes during cross-flow microfiltration of steepwater from corn starch industry. Many studies reported usage of the Kenics static mixers and its positive influence on the permeate flux increase during microfiltration of different feed suspensions (yeast, skim milk, wheat starch) as well as in wastewater treatment because of the unique flow patterns [8-11].

For several years, membrane separation processes have found their use in the starch production industry. This lead to a decrease in energy and wastewater disposal costs and increase in product quality regardless of the raw materials used [12]. Corn starch production usually at the beginning includes counter-current treatment of the kernels with a mixture of water and sulphur dioxide $(0.10 \%)$ in an appropriate rate at temperature $48{ }^{\circ} \mathrm{C}-52{ }^{\circ} \mathrm{C}$, within 30 to 40 hours [13]. This treatment known as steeping, later facilities separation of the germ and other components from the rest of the kernel which is further used in processing. The remaining water is known as steepwater which after treatment contains $6 \%-6.5 \%$ of dry matter basis originating from the kernels and is rich in soluble sugars, proteins and peptides, vitamins and minerals. For starch factory that processes $165 \mathrm{t}$ of kernels per day (kernel moisture $14 \%$ ) amount of water used for steeping is $1300 \mathrm{~L} / \mathrm{t}$ and the amount of steepwater that remains is $790 \mathrm{~L} / \mathrm{t}$ which is more than a half of water used. Steepwater as a valuable stream, after concentration to $35 \%$-50 \% dry matter and drying, can be further used as feedstock. However concentration costs are large and usually this water is discharged as wastewater. In this regard, membrane separation processes like microfiltration could be used instead of concentration which will reduce energy costs and provide protection of the environment from organic pollutants. Usage of microfiltration has already been investigated in starch production by several authors for isolation of starch [14] and starch nanocrystals [15], clarification of corn syrup [16] as well as in wastewater treatment [17].

As a well-established method for physical processes, response surface methodology (RSM) is used extensively in order to reduce the number of experiments, improve possibilities for statistical interpretation and estimate the impact of several affecting factors as well as their complex interactions [18]. When dealing with processes that have multi-responses, desirability function has shown as a method that is one of the most widely used for the optimization [19]. All mentioned indicates that for membrane separation processes as physical processes with multiple output parameters that are of interest, coupled response surface methodology and desirability function are fully applicable in order to obtain good optimization of the process. In this work, an attempt has been made to optimize the cross-flow microfiltration process using response surface methodology together with the desirability function approach. The aim of this research is to evaluate cross-flow microfiltration treatment of the steepwater from corn starch industry under the different range of transmembrane pressure (TMP) and crossflow velocities (Q) as well as permeate flux changes with and without embedded Kenics static mixer.

\section{Materials and methods}

Treated steepwater was obtained by corn starch processing plant "Jabuka" (Pančevo, Serbia) where the starch is produced by wet milling. The experiments were carried out using single channel ceramic membrane with pore sizes $100 \mathrm{~nm}$ from GEA manufacturer (Germany). The length of the membrane was 250 $\mathrm{mm}$ and useful membrane surface was $5 \times 10^{-3} \mathrm{~m}^{2}$. Inside the membrane tube, along the entire membrane length, stainless steel Kenics static mixer as a static turbulence promoter was set. Used Kenics static mixer had 30 helical mixing elements (diameter of $5 \mathrm{~mm}$ ) made from twisted $\left(180^{\circ}\right)$ thin flat strips. Every of 30 helical elements in the series was twisted for $90^{\circ}$ around its own axis compared to the neighbouring element [8].

Cross-flow microfiltration of steepwater is conducted in laboratory equipment (Fig. 1) on a transmembrane pressure in the range 1-3 bar and cross-flow velocities in the range of 100$200 \mathrm{~L} / \mathrm{h}$ at ambient temperature without static mixer (NSM) and with the static mixer (SM) inserted. Approximately $2.5 \mathrm{~L}$ of starting feed stream for each batch cross-flow microfiltration is prompted through the membrane module and system from the feed tank with a centrifugal pump at desired pressure and flow.

During experiments, the retentate was recirculated to the feed tank and permeate was collected in graduated vessel. Time needed for collection of every $10 \mathrm{~mL}$ of permeate was recorded. Every batch cross-flow microfiltration lasted about three hours and permeate flux was calculated from the measured times. After each experiment, the membrane was cleaned first with distilled water without recirculation $(5 \mathrm{~min})$ and with recirculation for $15 \mathrm{~min}$ in order to remove residual matters from feed stream and then with $0.5 \%$ Ultrasil 11 solution with recirculation for two hours. Before every experiment, examination of the distilled water flux was carried out in order to evaluate the membrane cleaning procedure effectiveness and bring the flux of distilled water to the closest value for a clean membrane. 
Table 1 Central composite design (in coded level of variables) and responses with corresponding desirability functions

\begin{tabular}{|c|c|c|c|c|c|c|c|c|}
\hline \multirow{2}{*}{$\begin{array}{l}\text { Exp. } \\
\text { number }\end{array}$} & \multirow{2}{*}{$\begin{array}{l}\text { TMP (bar) } \\
\mathrm{X}_{1}\left(\mathrm{x}_{1}\right)\end{array}$} & \multirow{2}{*}{$\begin{array}{l}\mathrm{Q}(\mathrm{L} / \mathrm{h}) \\
\mathrm{X}_{2}\left(\mathrm{x}_{2}\right)\end{array}$} & \multirow{2}{*}{$\mathrm{J}_{\mathrm{NSM}}\left(\mathrm{L} / \mathrm{m}^{2} \mathrm{~h}\right)$} & \multirow{2}{*}{$\mathrm{J}_{\mathrm{SM}}\left(\mathrm{L} / \mathrm{m}^{2} \mathrm{~h}\right)$} & \multirow{2}{*}{ FI (\%) } & \multirow{2}{*}{ ER $(\%)$} & \multirow{2}{*}{$\begin{array}{l}\text { Desirability } \\
\text { function* }\end{array}$} & \multirow{2}{*}{$\begin{array}{l}\text { Desirability } \\
\text { function** }\end{array}$} \\
\hline & & & & & & & & \\
\hline 1 & $1(-1)$ & $100(-1)$ & 28 & 60 & 114.29 & 6.67 & 0.597 & 0.658 \\
\hline 2 & $2(0)$ & $100(-1)$ & 21 & 44.06 & 109.81 & 4.68 & 0.078 & 0.136 \\
\hline 3 & $3(1)$ & $100(-1)$ & 20.84 & 48.87 & 134.50 & 14.71 & 0.435 & 0.536 \\
\hline 4 & $1(-1)$ & $150(0)$ & 30 & 65.22 & 117.40 & -15.00 & 0.639 & 0.614 \\
\hline 5 & $2(0)$ & $150(0)$ & 26.97 & 52.26 & 93.77 & -29.02 & 0.237 & 0.244 \\
\hline 6 & $3(1)$ & $150(0)$ & 24.93 & 55.78 & 123.75 & -11.73 & 0.348 & 0.375 \\
\hline 7 & $1(-1)$ & $200(1)$ & 29.46 & 78.43 & 166.23 & -12.69 & 0.665 & 0.612 \\
\hline 8 & $2(0)$ & $200(1)$ & 24.83 & 51.5 & 107.41 & -44.64 & 0.120 & 0.100 \\
\hline 9 & $3(1)$ & $200(1)$ & 22.27 & 48.52 & 117.87 & -37.70 & 0.141 & 0.136 \\
\hline 10 & $2(0)$ & $150(0)$ & 25.47 & 51.41 & 101.84 & -30.02 & 0.237 & 0.244 \\
\hline 11 & $2(0)$ & $150(0)$ & 25.98 & 52.04 & 100.31 & -29.87 & 0.237 & 0.244 \\
\hline
\end{tabular}

TMP-transmembrane pressure, Q-steepwater cross-flow rate, $\mathrm{J}_{\mathrm{NSM}}$-average permeate flux without static mixer, $\mathrm{J}_{\mathrm{SM}}$-average permeate flux with static mixer, FI-permeate flux improvement, ER-reduction of specific energy consumption. Desirability function*-the same significance of $\mathrm{J}_{\mathrm{SM}}$ and ER, Desirability function**-the highest significance of ER compared to $\mathrm{J}_{\mathrm{SM}}$.

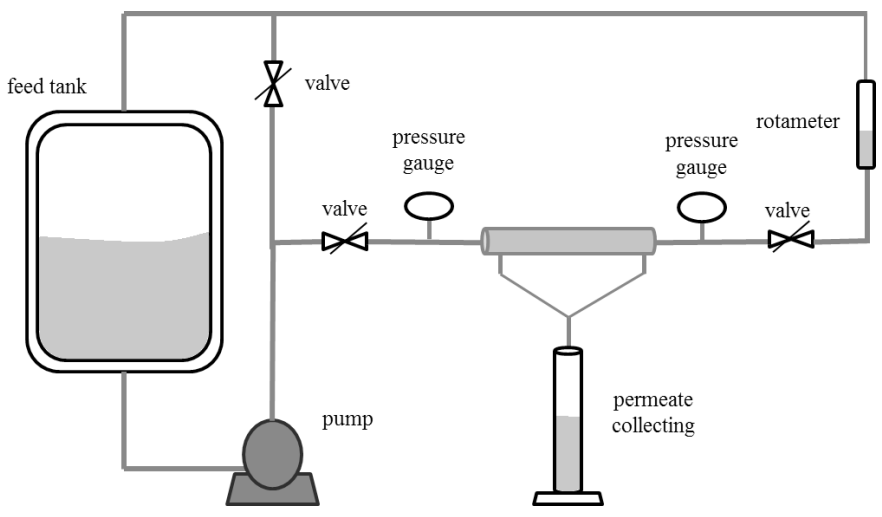

Fig. 1 Schematic representation of experimental set-up for cross-flow microfiltration

\subsection{Design of Experiment and Statistical Analysis}

The whole experiment was designed according to central composite design of face-centered type with independent variables, transmembrane pressure and cross-flow velocity, on three levels (1, 2, 3 bar for TMP and 100, 150 and $200 \mathrm{~L} / \mathrm{h}$ for Q) so the total number of experiments was eleven including two repetitions of central point. Permeate flux was calculated according to the formula:

$$
J=V / A \times t \quad\left[\mathrm{~L} / \mathrm{m}^{2} \mathrm{~h}\right]
$$

where $J$ is permeate flux $\left(\mathrm{L} / \mathrm{m}^{2} \mathrm{~h}\right), V$ is collected permeate volume $(\mathrm{L}), A$ is membrane surface $\left(\mathrm{m}^{2}\right)$ and $t$ is time of microfiltration.

For evaluation and quantifying the influence of the variables obtained after experiments, common second degree polynomial model was used:

$$
Y=b_{0}+\sum b_{i} X_{i}+\sum b_{i i} X_{i i}^{2}+\sum \sum b_{i j} X_{i} X_{j}
$$

where $Y$ represents response, $X_{i}$ represents levels of input factors, $b_{0}$ is intercept, $\mathrm{b}_{i}$ represents linear coefficient, $b_{i i}$ quadratic coefficient and $b_{i j}$ is the coefficient of interaction. These regression coefficients can give information about the influence of the individual factors with consideration of the effects that occur among them. Responses that were fitted with the presented polynomial model were: $\mathrm{J}_{\mathrm{NSM}}$-permeate flux without static mixer; $\mathrm{J}_{\mathrm{SM}}$-permeate flux with a static mixer; FI-permeate flux improvement; ER-reduction of specific energy consumption and are given in Table 1.

The permeate flux during microfiltration influenced by Kenics static mixer was determined as permeate flux improvement (FI) which was defined as the relative increase in permeate flux during usage of static mixer and was calculated by formula [8]:

$$
F I=\left(J_{S M}-J_{N S M} / J_{N S M}\right) \times 100 \quad[\%]
$$

where $J_{S M}$ represents permeate flux with a static mixer and $J_{N S M}$ is permeate flux without the static mixer.

The efficiency of the Kenics static mixer as a turbulence promoter was determined by reduction of specific energy consumption (ER) which is one of the leading parameter of importance from the economic viewpoint. Specific energy consumption was defined as the power dissipated per unit volume of permeates and can be calculated as follows [8]:

$$
E=P / J_{p} \times A \quad\left[\mathrm{kWh} / \mathrm{m}^{3}\right]
$$

where $E$ is the specific energy consumption $\left(\mathrm{kWh} / \mathrm{m}^{3}\right), P$ is the hydraulic dissipated power (W), $J_{p}$ the permeate flux $\left(\mathrm{L} / \mathrm{m}^{2} \mathrm{~h}\right)$ and $A$ membrane surface $\left(\mathrm{m}^{2}\right)$.

By multiplication of feed flow rate and pressure drop along the module the hydraulic dissipated power can be calculated [10]: 


$$
P=Q \times \Delta P \quad[\mathrm{~W}]
$$

where $P$ is the hydraulic dissipated power (W), $Q$ is feed flow rate $(\mathrm{L} / \mathrm{h})$ and $\Delta P$ pressure drop (bar).

Reduction of specific energy consumption can be calculated as follows [8]:

$$
E R=\left(E_{N S M}-E_{S M} / E_{N S M}\right) \times 100 \quad[\%]
$$

where $E R$ is the reduction of specific energy consumption (\%), $E_{N S M}$ and $E_{S M}$ are specific energy consumptions without the static mixer and with the static mixer $\left(\mathrm{kWh} / \mathrm{m}^{3}\right)$ respectively.

The suitability of proposed model was evaluated by the coefficient of determination $\left(\mathrm{R}^{2}\right)$ and model $\mathrm{p}$-value. Determination of significance for each factor and their interactions is conducted by comparing the p-values. Once an adjusted response to the polynomial model has been obtained, the best conditions of microfiltration process were defined using desirability function. For graphical representation of the results Statistica ${ }^{\circledR}$ software was used while desirability function was calculated using Design Expert ${ }^{\circledR}$ software.

\section{Results and discussion}

Obtained results of the statistical analysis according to the central composite experimental plan are shown in Table 2 and results of the ANOVA analysis are reported in Table 3 for modelled responses. Relatively high values of $\mathrm{R}^{2}$ obtained for all responses indicate a good fit of experimental data with Eq. (1). The significance of each coefficient was determined through p-values with whose increase in magnitude the significance of the corresponding coefficient is decreasing. All polynomial models tested for the selected responses were significant at 0.05 significance level (p-value: 0.05 , Table 3 ).

\subsection{Permeate Flux without Static Mixer (NSM)}

Obtained results of fitting the experimental values of the average permeate flux with the second order polynomial without the application of the static mixer are shown in Table 2. The suitability of model fit is checked by the determination coefficient $\left(\mathrm{R}^{2}\right)$ that is found to be 0.9483 (Table 3). This value of $R^{2}$ indicates that the presented model does not cover about $5 \%$ of the variations. The most important linear factor influencing the average permeate flux in the system without the static mixer is the steepwater cross-flow rate $(0.0065)$ as well as among the quadratic factors (0.0073). Likewise, transmembrane pressure factors, both linear and quadratic, are statistically significant while the mutual interaction in the system without the static mixer between transmembrane pressure and steepwater cross-flow rate is not significant at 0.05 significance level. The effects of the transmembrane pressure and steepwater cross-flow rate in the system without static mixer on permeate flux are shown in Fig. 2. According to the figure, an initial increase in permeate flux value is recorded at both, low and high transmembrane pressures with increasing cross-flow rate. After achieving the maximal value, permeate flux slightly decreases with additional cross-flow rate increase. This slight decrease in the permeate flux may be explained as a consequence of precipitation of smaller diameter particles from the feed stream during time at higher transmembrane pressure into the membrane pores. This way membrane pores are blocked by the small particles and together with the accumulation of the suspension particles on membrane surface have an influence on the average permeate flux e.g. its reduction [20]. Particles precipitation on membrane surface during microfiltration process arises from the fact that a combination of several forces is acting on particles from the feed stream. In the vicinity of the membrane, drag force of the filtrate flow and lift force have an influence on the suspension particles and cause their deposition on the membrane surface. After deposition, particles are affected by the adhesive Van der Waals forces that are acting on them [21]. As a result of the acting forces, smaller diameter particles are deposited which leads to the formation of less porous filtration cake. Compact filter cake occurs at higher transmembrane pressure and leads to flux reduction which is a negative effect of higher transmembrane pressure [22, 23].

At higher suspension flow rates, between $150 \mathrm{~L} / \mathrm{h}$ and $175 \mathrm{~L} / \mathrm{h}$, and increasing transmembrane pressure, the permeate flux demonstrate decreasing values (Fig. 2).

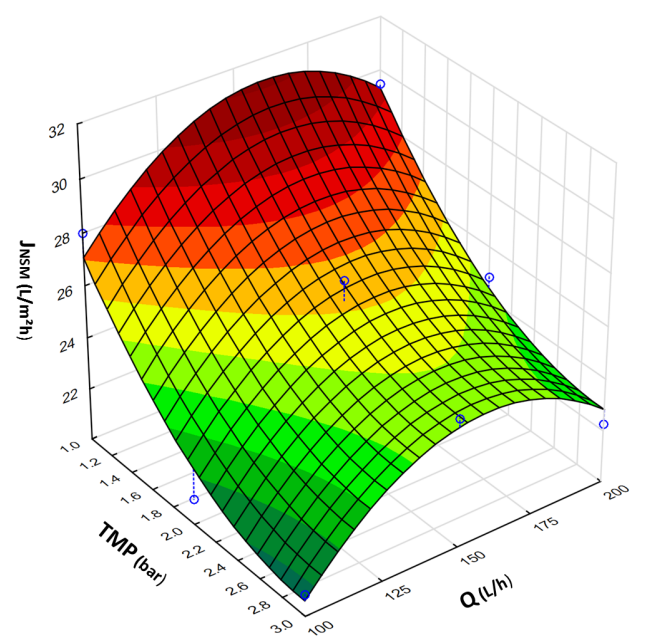

Fig. 2 Effects of transmembrane pressure and cross-flow rate on average permeate flux without static mixer; $\mathrm{J}_{\mathrm{NSM}}$-average permeate flux without static mixer; TMP-transmembrane pressure; Q-steepwater cross-flow rate

With further flow rate increase, permeate flux slightly decreases. Possible explanation for this decrease is that transmembrane pressure increase leads to clogging of the membrane pores so the positive effect of increasing the flow cannot be expressed. The positive impact of higher feed flow rates is reflected in a higher tangential shear stress near the membrane surface and the reduction of the thickness of the filter cake because of particles instability on the membrane surface. Average permeate flux is increasing as a consequence of this phenomenon. 
Table 2 Regression equation coefficients for responses

\begin{tabular}{|c|c|c|c|c|c|c|c|c|}
\hline \multirow[t]{2}{*}{ Effects } & \multicolumn{2}{|c|}{$\mathrm{J}_{\mathrm{NSM}}\left(\mathrm{L} / \mathrm{m}^{2} \mathrm{~h}\right)$} & \multicolumn{2}{|c|}{$\mathrm{J}_{\mathrm{SM}}\left(\mathrm{L} / \mathrm{m}^{2} \mathrm{~h}\right)$} & \multicolumn{2}{|c|}{ FI $(\%)$} & \multicolumn{2}{|c|}{ ER (\%) } \\
\hline & Estimate & p-value & Estimate & p-value & Estimate & p-value & Estimate & $\mathrm{p}$-value \\
\hline \multicolumn{9}{|c|}{ Intercept } \\
\hline $\mathrm{b}_{0}$ & 25.95 & 0.1235 & 51.36 & 0.0747 & 98.08 & $0.0137 *$ & -28.89 & $0.0117 *$ \\
\hline \multicolumn{9}{|l|}{ Linear } \\
\hline $\mathrm{b}_{1}$ & -3.24 & $0.0172 *$ & -8.41 & $0.0127 *$ & -3.63 & 0.1093 & -2.28 & 0.0558 \\
\hline $\mathrm{b}_{2}$ & 1.12 & $0.0065^{*}$ & 4.25 & 0.0524 & 5.48 & 0.4013 & -20.18 & $0.0436^{*}$ \\
\hline \multicolumn{9}{|c|}{ Quadratic } \\
\hline $\mathrm{b}_{11}$ & 1.80 & $0.0358^{*}$ & 9.95 & $0.0034 *$ & 23.34 & $0.0054 *$ & 14.41 & $0.0049^{*}$ \\
\hline $\mathrm{b}_{22}$ & -2.75 & 0.0073 & -2.77 & 0.2078 & 11.38 & 0.0712 & 7.79 & $0.0489^{*}$ \\
\hline \multicolumn{9}{|c|}{ Interaction } \\
\hline$b_{12}$ & $-7.5 \mathrm{E}-03$ & 0.9887 & -4.70 & $0.0273 *$ & -17.14 & $0.0075^{*}$ & -8.26 & $0.0182 *$ \\
\hline
\end{tabular}

Table 3 Analysis of variance (ANOVA) of the modeled responses

\begin{tabular}{|c|c|c|c|c|c|c|c|c|c|c|}
\hline \multirow[t]{3}{*}{ Response } & \multicolumn{10}{|c|}{ Source } \\
\hline & \multicolumn{3}{|c|}{ Residual } & & & \multicolumn{2}{|l|}{ Model } & \multirow[b]{2}{*}{$\mathrm{p}$-value } & \multirow[b]{2}{*}{$\mathrm{R}^{2}$} & \multirow[b]{2}{*}{$\operatorname{adj} R^{2}$} \\
\hline & DF & SS & MS & DF & SS & MS & F-value & & & \\
\hline $\mathrm{J}_{\mathrm{NSM}}\left(\mathrm{L} / \mathrm{m}^{2} \mathrm{~h}\right)$ & 5 & 5.05 & 1.01 & 5 & 92.64 & 18.53 & 18.34 & 0.0031 & 0.9483 & 0.8966 \\
\hline $\mathrm{J}_{\mathrm{SM}}\left(\mathrm{L} / \mathrm{m}^{2} \mathrm{~h}\right)$ & 5 & 46.36 & 9.27 & 5 & 827.45 & 174.49 & 18.82 & 0.0029 & 0.9495 & 0.8991 \\
\hline FI (\%) & 5 & 314.40 & 62.88 & 5 & 3660.94 & 732.19 & 11.64 & 0.0088 & 0.9209 & 0.8418 \\
\hline ER (\%) & 5 & 114.74 & 22.95 & 5 & 3643.00 & 728.60 & 31.75 & 0.0009 & 0.9695 & 0.9389 \\
\hline
\end{tabular}

$\mathrm{J}_{\mathrm{NSM}}$-average permeate flux without static mixer; $\mathrm{J}_{\mathrm{SM}}$-average permeate flux with static mixer; FI-permeate flux improvement; ER-reduction of specific energy consumption; DF-degree of freedom; SS-sum of squares; MS-mean squares

\subsection{Permeate Flux with Static Mixer (SM)}

Results of fitting the experimental data of the average permeate flux with the second order polynomial in the system with the static mixer (SM) are shown in Table 2. In this system, when using a static mixer, the coefficient of determination was found to be 0.9495 (Table 3) and is slightly higher than that reported for the system without the static mixer, indicating that less than $6 \%$ of the variations could not be covered by the presented model. Among the linear factors, significant impact on the average permeate flux in the system with the static mixer has transmembrane pressure likewise in the results obtained for system without the static mixer. The most significant quadratic factor is the transmembrane pressure (0.0034) and interaction in the system with the static mixer between transmembrane pressure and steepwater cross-flow rate is significant at 0.05 significance level unlike, the system without the static mixer (Table 2). The effects of the transmembrane pressure and steepwater cross-flow rate in the system with static mixer on permeate flux are shown in Fig. 3. Permeate flux increase in this system is noticeable at lower transmembrane pressures at all cross-flow rates. Influence of transmembrane pressure on permeate flux is more pronounced at higher flow rates because of the thinner cake formation at this rates. The presence of the static mixer has positive effects on the average permeate flux improvement.

It is noted that permeate flux improves for $269 \%$ during microfiltration with inserted static mixer in comparison to the flux obtained in the microfiltration process without the static mixer (Table 1). With insertion of static mixer or any other turbulence promoter into ceramic membrane tube changes occur in the way of fluid flow. Under the same process conditions for systems with and without static mixer, better improvement of the permeate flux is noticed in system with the presence of static mixer because of his influence on the fluid stream movement near the surface of the membrane, so that the flow rate along the membrane increased relative to the speed of suspension flow in the system [8].

The most evident increase in permeate flux is at lower transmembrane pressures with the increase in the suspension flow rate, although the same trend is observed at higher transmembrane pressures but is not that expressed. The assumption is that due to the intense mixing and creation of the secondary flows, presence of static mixer reduces the possibility of penetration and clogging of the membrane pores. Similar observations 


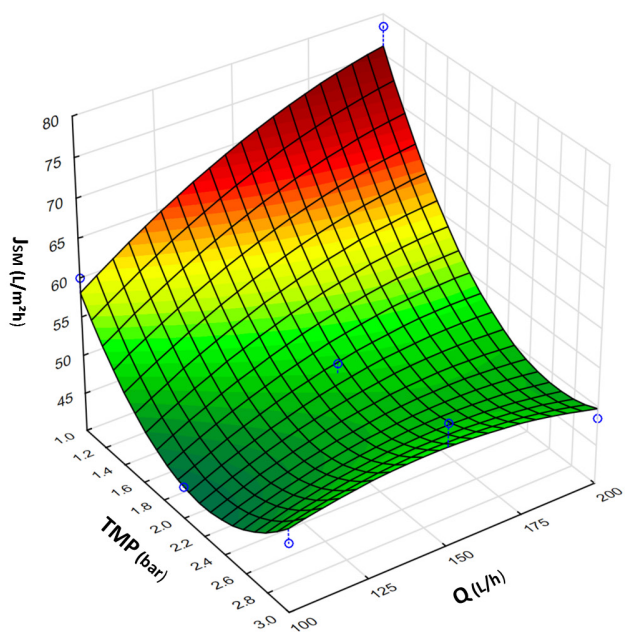

Fig. 3 Effects of transmembrane pressure and cross-flow rate on average permeate flux with static mixer; $\mathrm{J}_{\mathrm{SM}}$-average permeate flux with static mixer; TMP-transmembrane pressure; Q-steepwater cross-flow rate

when using the Kenics static mixer were recorded in studies of Jokić et al. [8] and Ikonić et al. [10].

\subsection{Average Permeate Flux Improvement}

With obtained determination coefficient that for the response of improvement of permeation flux was found to be 0.9209 (Table 3 ) the adequacy of model fit is checked and result indicates that $8 \%$ of the variations could not be covered by the presented model. According to the values obtained for polynomial coefficients, among the linear factors on the permeate flux improvement neither transmembrane pressure nor steepwater cross-flow rate had significant influence. The transmembrane pressure is the most significant quadratic factor (0.0054) while the interaction between the transmembrane pressure and steepwater cross-flow rate had an influence on the average permeate flux improvement which was significant at the 0.05 significance level (Table 2).

The influence of transmembrane pressure and cross-flow rate on the average permeate flux improvement is shown on Fig. 4. Observing Fig. 4, it can be seen that at low values of transmembrane pressure with increasing steepwater cross-flow rate the average permeate flux increases rapidly in the presence of static mixer. The maximum increase in the average permeate flux appears at the transmembrane pressure of 1 bar and maximal steepwater cross-flow rate, probably because there has been no clogging of pores at the beginning of the microfiltration in the system with embedded static mixer. With the usage of the static mixer certain increase in the average permeate flux values is achieved at low steepwater cross-flow rates.

\subsection{Reduction of Specific Energy Consumption}

Specific energy consumption as a function of pressure drop along the membrane tube, average permeate flux achieved for particular experimental conditions and membrane surface area

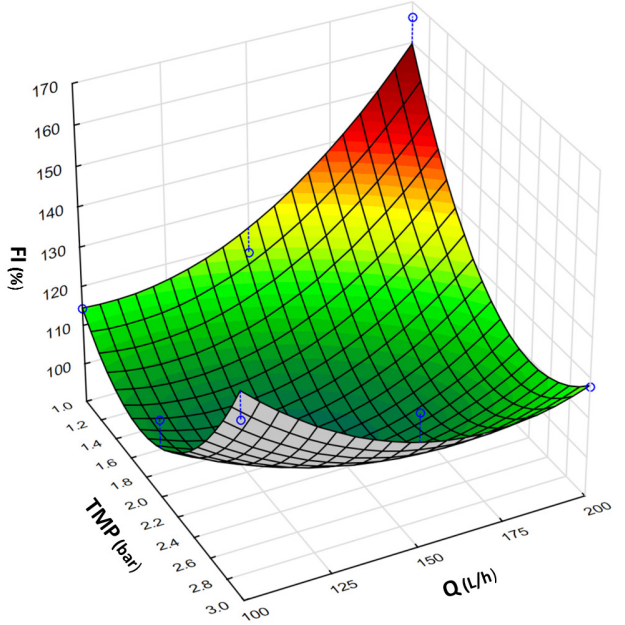

Fig. 4 Effects of transmembrane pressure and cross-flow rate on average permeate flux improvement; FI-permeate flux improvement; TMP-

transmembrane pressure; Q-steepwater cross-flow rate

is one of the most important parameters from the economic standpoint. Insertion of the static mixer into the membrane tube inevitably leads to certain changes in pressure drop and average permeate flux. First change occurs in pressure drop along the membrane which is rising because of the increased resistance to feed flow. Second change occurs in the permeate flux which is increasing due to the changes in fluid flow through the membrane [8]. As far from the economic standpoint, the goal is to reach the highest value of the reduction of specific energy consumption what would justify the use of the static mixer. Achievement of high values of reduction of specific energy consumption is possible in cases when an increase in the permeate flux is high enough to compensate the increase in pressure drop along the membrane tube [10]. The goodness of model fit was checked by the determination coefficient that for the response of reduction of specific energy consumption was found to be 0.967 (Table 3) which indicates that $3.3 \%$ of the variations could not be covered by the presented model. As for the significance of the polynomial coefficient, approximate values are obtained for both linear factors but one with the significant influence on the reduction of specific energy consumption was steepwater cross-flow rate (Table 2). Both quadratic factors had effect on the reduction of specific energy consumption, but more pronounced influence had transmembrane pressure (0.0049), also the mutual interaction between transmembrane pressure and steepwater cross-flow rate was significant at 0.05 significance level (Table 3). Fig. 5 shows the effects of steepwater cross-flow rate and transmembrane pressure on the reduction of specific energy consumption. The increase in feed flow rates resulted in a decrease of the reduction of specific energy consumption at values of transmembrane pressure 2 and 3 bar. With further decrease in transmembrane pressure reduction of specific energy consumption increases at all values of feed cross-flow rate. The maximum 
Table 4 Results of microfiltration process optimization

\begin{tabular}{|c|c|c|c|c|c|c|}
\hline \multicolumn{2}{|c|}{ Factor significance } & \multirow{2}{*}{ TMP (bar) } & \multirow{2}{*}{$\mathrm{Q}(\mathrm{L} / \mathrm{h})$} & \multirow{2}{*}{$\mathrm{J}_{\mathrm{SM}}\left(\mathrm{L} / \mathrm{m}^{2} \mathrm{~h}\right)$} & \multirow{2}{*}{ ER (\%) } & \multirow{2}{*}{$\begin{array}{l}\text { Overall Desirability } \\
\text { function }\end{array}$} \\
\hline $\mathrm{J}_{\mathrm{SM}}$ & ER & & & & & \\
\hline 3 & 3 & 1 & 200 & 75.9096 & -16.3287 & 0.665 \\
\hline 3 & 3 & 1 & 138.49 & 67.5206 & -9.04353 & 0.640 \\
\hline 3 & 3 & 1 & 139.25 & 67.6759 & -9.27837 & 0.640 \\
\hline 3 & 3 & 1 & 140.00 & 67.8269 & -9.50495 & 0.640 \\
\hline 3 & 5 & 1 & 106.46 & 59.8377 & 4.08641 & 0.660 \\
\hline 3 & 5 & 1 & 106.03 & 59.7183 & 4.30769 & 0.660 \\
\hline 3 & 5 & 1 & 200.00 & 75.9096 & -16.3287 & 0.612 \\
\hline 3 & 5 & 1 & 157.50 & 71.0075 & -13.8135 & 0.606 \\
\hline
\end{tabular}

TMP-transmembrane pressure; Q-steepwater cross-flow rate; $\mathrm{J}_{\mathrm{SM}}$-average permeate flux with static mixer; ER-reduction of specific energy consumption

positive value of the reduction of specific energy consumption is achieved at the minimum cross-flow rate and value of transmembrane pressure close to maximal.

\subsection{Optimization of the Microfiltration Process Using Desirability Function Approach}

When many factors and interactions are affecting the response variables, response surface methodology (RSM) is an effective tool for optimizing experimental processes. The use of RSM has been focused in most of the works on the case where there is only one response of interest.

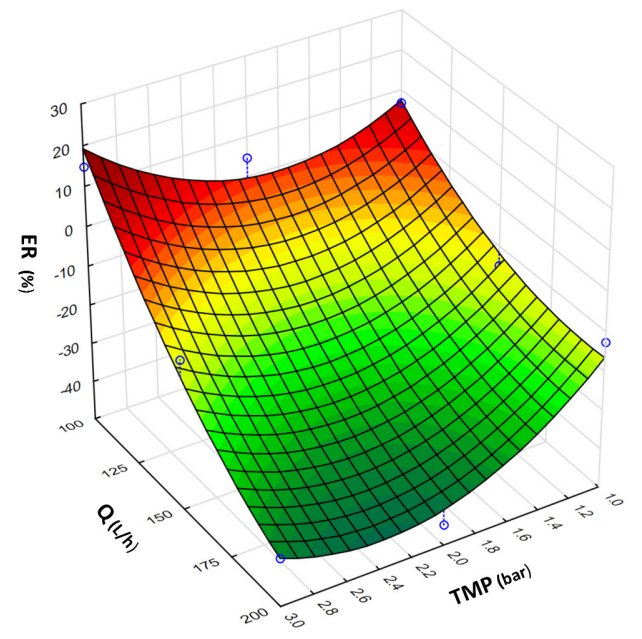

Fig. 5 Effects of transmembrane pressure and cross-flow rate on specific energy consumption; ER-reduction of specific energy consumption; TMP-transmembrane pressure; Q-steepwater cross-flow rate

There are cases with several response variables of interest or the relationship between the response variables and design variables is too complex to be efficiently estimated using traditional surface fitting approaches [24]. Transformation of a multiple response problem into a single response problem by means of mathematical transformations represents the basic idea of the desirability function approach [25] which is used for description of simultaneous optimum conditions for all significant responses [26]. The concept of this function is that the quality of a product or process that has many responses is completely unacceptable if one of them is outside of a "desirable" limit. Desirability always takes values in the range of 0 to 1 , where 0 is an undesirable response, and 1 represents an ideal response. For more or less desirable responses desirability function takes intermediate values [27]. Each obtained response has an individual desirability value ranging from 0 to 1 . Computed geometric mean of the individual desirability functions represents the overall desirability of the process [28]. In this work for optimization of microfiltration of steepwater from corn starch industry selected responses were average permeate flux in system with a static mixer $\left(\mathrm{J}_{\mathrm{SM}}\right)$ and reduction of specific energy consumption (ER). The optimization objective was to select the transmembrane pressure and steepwater cross-flow rate at which selected responses will have a maximal value of individual desirability functions what will give a greater value of overall desirability. The optimal values of the transmembrane pressure and cross-flow rate depending on the factors of significance of individual responses as well as the value of optimized responses are presented in Table 4.

The calculations were performed with Design Expert ${ }^{\circledR}$ software. The values of transmembrane pressure and steepwater crossflow rate were set in the experimental range. At the same level of significance of the observed responses, optimal conditions for performing the process of microfiltration are at feed cross-flow rate $200 \mathrm{~L} / \mathrm{h}$ and transmembrane pressure $1 \mathrm{bar}$, but resulted in a negative value of reduction of specific energy consumption which does not justify the use of Kenics static mixer. With increased factor of significance for reduction of specific energy consumption positive value of ER is achieved and optimal values are low steepwater cross-flow rate $(106.03$ and $106.46 \mathrm{~L} / \mathrm{h})$ and transmembrane pressure of 1 bar. Comparing individual desirability values from the Table 1 with the results from the Table 4 it can be seen that the found optimal solution has a higher global desirability value than initial points reported in Table 1. 


\section{Conclusions}

Improvement in microfiltration process of steepwater from corn starch industry with embedded Kenics static mixer was achieved at lower cross-flow rates and transmembrane pressures. When compared to the system without Kenics static mixer the average permeate flux improved for $211 \%$ to $269 \%$ depending on experimental conditions. Reduction of specific energy consumption decreases with the increase of cross-flow rate because the permeate flux is not high enough to compensate the increase in pressure drop along the membrane tube. For mathematical representation of the process response surface methodology was applied and confirmed to be adequate modelling tool. Desirability function approach was used for determination of the optimal conditions for microfiltration. At steepwater cross-flow rate $107.17 \mathrm{~L} / \mathrm{h}$ and transmembrane pressure 1 bar positive value of reduction of specific energy consumption was obtained which justifies the use of Kenics static mixer as a turbulence promoter. The proposed microfiltration process together with the obtained optimized parameters has potential use in the industries which are dealing with wastewater treatment as well as in other industries that are working with similar streams.

\section{Acknowledgement}

This work was supported by the Ministry of Education, Science and Technological development of Serbia.

\section{References}

[1] Kralj, A. K. "The re-usages of wastewater within industry: the positive impact of contaminants." Journal of Cleaner Production. 95, pp. 124130. 2015. https://doi.org/10.1016/j.jclepro.2015.02.054

[2] Šereš, Z., Maravić, N., Takači, A., Nikolić, I., Šoronja-Simović, D., Jokić, A., Hodur, C. "Treatment of vegetable oil refinery wastewater using alumina ceramic membrane: optimization using response surface methodology." Journal of Cleaner Production. 112, pp. 3132-3137. 2016. https://doi.org/10.1016/j.jclepro.2015.10.070

[3] Vinoth Kumar, R., Ghoshal, A. K., Pugazhenthi, G. "Elaboration of novel tubular ceramic membrane from inexpensive raw materials by extrusion method and its performance in microfiltration of synthetic oily wastewater treatment." Journal of Membrane Science. 490, pp. 92-102. 2015. https://doi.org/10.1016/j.memsci.2015.04.066

[4] Gupta, B. B., Howell, J.A., Wu, D. R., Field, W. "A helical baffle for cross-flow microfiltration." Journal of Membrane Science. 99, pp. 31-42. 1995. https://doi.org/10.1016/0376-7388(94)00241-P

[5] Baker, R. W. "Membrane Technology and Application." Second edition. Wiley, New York, NY. 2004.

[6] Hashemi Shahraki, M., Maskooki, A., Faezian, A. "Hollow Fibers Filtration and Cleaning Processes Under Ultrasound and Gas Bubbling Combination." Journal of Food Process Engineering. 40, e12325. 2017. https://doi.org/10.1111/jfpe.12325

[7] Mazubert, A., Poux, M., Aubin, J. "Intensified processes for FAME production from waste cooking oil: A technological review." Chemical Engineering Journal. 233, pp. 201-223. 2013. https://doi.org/10.1016/j.cej.2013.07.063
[8] Jokić, A., Zavargo, Z., Šereš, Z., Tekić, M. "The effect of turbulence promoter on cross-flow microfiltration of yeast suspensions: A response surface methodology approach." Journal of Membrane Science. 350, pp. 269-278. 2010. https://doi.org/10.1016/j.memsci.2009.12.037

[9] Krstić, D. M., Tekić, M. N., Carić, M. D., Milanović, S. D. "Static turbulence promoter in cross-flow microfiltration of skim milk." Desalination. 163, pp. 297-309. 2004.

https://doi.org/10.1016/S0011-9164(04)90203-2

[10] Ikonić, B., Zavargo, Z., Šereš, Z., Gyura, J., Jokić, A. "Flux Improvement during Cross-flow Microfiltration of Wheat Starch Suspension using Turbulence Promoter." Separation Science and Technology. 47, pp. 972-982. 2012. https://doi.org/10.1080/01496395.2011.640379

[11] Šereš, Z., Dokić, L., Pajin, B., Šoronja-Simović, D., Šubarić, D., Babić, J., Fišteš, A. "Influence of the operating parameters on the flux during microfiltration of the steepwater in the starch industry." Acta Periodica Technologica. 43, pp. 225-235. 2012. https://doi.org/10.2298/APT1243225S

[12] Rausch, K. D. "Front End to Backpipe: Membrane Technology in the Starch Processing Industry." Starch/Stärke. 54, pp. 273-284. 2002. https://doi.org/10.1002/1521-379X(200207)54:7<273::AIDSTAR2222273>3.0.CO;2-\#

[13] Daniel, J. R., Whistler, R. L., Roper, H., Elvers, B. "Starch." In: Ullmann's Encyclopedia of Industrial Chemistry 7th ed. Wiley-VCH, Ed., Weinheim. 2007.

[14] Cancino-Madariaga, B., Aguirre, J. "Combination treatment of corn starch wastewater by sedimentation, microfiltration and reverse osmosis." Desalination. 279, pp. 285-290. 2011. https://doi.org/10.1016/j.desal.2011.06.021

[15] Romdhane, A., Aurousseau, M., Guillet, A., Mauret, E. "Cross Flow Microfiltration of Starch Nanocrystal Suspensions." The Canadian Journal of Chemical Engineering. 93, pp. 412-418. 2015. https://doi.org/10.1002/cjce.22092

[16] Almandoz, C., Pagliero, C., Ochoa, A., Marchese, J. "Corn syrup clarification by microfiltration with ceramic membranes." Journal of Membrane Science. 363, pp. 87-95. 2010. https://doi.org/10.1016/j.memsci.2010.07.017

[17] Šaranović, Z., Šereš, Z., Jokić, A., Pajin, B., Dokić, Lj., Gyura, J., Dalmacija, B., Šoronja Simović, D. "Reduction of solid content in starch industry wastewater by microfiltration." Starch/Stärke. 63, pp. 64-74. 2011. https://doi.org/10.1002/star.201000077

[18] Manivannan, P., Rajasimman, M. "Optimization of Process Parameters for the Osmotic Dehydration of Beetroot in Sugar Solution." Journal of Food Process Engineering. 34, pp. 804-825. 2011. https://doi.org/10.1111/j.1745-4530.2009.00436.x

[19] Li, H., Chen, J., Xiao, Y. "Multi-objective optimization for laminated steel sheet forming process based on desirability function approach and reliability analysis." Engineering Computations. 30(8), pp. 1107-1127. 2013. https://doi.org/10.1108/EC-08-2012-0179

[20] Ousman, M., Bennasar, M. "Determination of various hydraulic resistances during cross-flow filtration of a starch grain suspension through inorganic membranes." Journal of Membrane Science. 105(1-2), pp. 1-21. 1995.

[21] Zhong, Z., Xing, W., Liu, X., Jin, W., Xu, N. "Fouling and regeneration of ceramic membranes used in recovering titanium silicalite-1 catalysts." Journal of Membrane Science. 301(1-2), pp. 67-75. 2007. https://doi.org/10.1016/j.memsci.2007.05.036

[22] Hwang, K.-J., Hsu, Y.-L., Tung, K.-L. "Effect of particle size on the performance of cross-flow microfiltration." Advanced Powder Technology. 17(2), pp. 189-206. 2006. https://doi.org/10.1163/156855206775992292 
[23] Lee, Y., Clark, M. M. "Modeling of flux decline during cross-flow ultrafiltration of colloidal suspensions." Journal of Membrane Science. 149(2), pp. 181-202. 1998.

[24] Pu, J.-B., Xia, B.-H., Hu, Y.-J., Zhang, H.-J., Chen, J., Zhou, J., Liang, W.-Q., Xu, P. "Multi-Optimization of Ultrasonic-Assisted Enzymatic Extraction of Atratylodes macrocephala Polysaccharides and Antioxidants Using Response Surface Methodology and Desirability Function Approach." Molecules. 20(12), pp. 22220-22235. 2015.

https://doi.org/10.3390/molecules201219837

[25] Lazo-Vélez, M. A., Avilés-González, J., Serna-Saldivar, S. O., TembladorPérez, M.C. "Optimization of wheat sprouting for production of selenium enriched kernels using response surface methodology and desirability function." LWT - Food Science and Technology. 65, pp. 1080-1086. 2016. https://doi.org/10.1016/j.lwt.2015.08.056
[26] Borges, L. L., Martins, F. S., Conceição, E. C., Silveira, D. "Optimization of the Spray-Drying Process for Developing Jabuticaba Waste Powder Employing Response Surface Methodology." Journal of Food Process Engineering. 40(1), e12276. 2017.

https://doi.org/10.1111/jfpe.12276

[27] Vera Candioti, L., De Zan, M. M., Cámara, M. S., Goicoechea, H. C. "Experimental design and multiple response optimization. Using the desirability function in analytical methods development." Talanta. 124, pp. 123-138. 2014. https://doi.org/10.1016/j.talanta.2014.01.034

[28] Cojocaru, C., Khayet, M., Zakrzewska-Trznadel, G., Jaworska, A. "Modeling and multi-response optimization of pervaporation of organic aqueous solutions using desirability function approach." Journal of Hazardous Materials. 167. pp. 52-63. 2009.

https://doi.org/10.1016/j.jhazmat.2008.12.078 